\title{
Correction to: Will the Real Theoretical Structure of the WISC-V Please Stand Up? Implications for Clinical Interpretation
}

\author{
Stefan C. Dombrowski ${ }^{1}$ - Ryan J. McGill ${ }^{2}$ Marley W. Watkins ${ }^{3} \cdot$ Gary L. Canivez ${ }^{4}$ - Alison E. Pritchard ${ }^{5}$. \\ Lisa A. Jacobson ${ }^{5}$
}

Published online: 26 April 2021

(C) California Association of School Psychologists 2021

\section{Correction to: Contemporary School Psychology. https://doi.org/10.1007/s40688-021-00365-6}

Due to a Production error the last sentence of the article was incorrect.

The original article has been corrected.

Publisher's Note Springer Nature remains neutral with regard to jurisdictional claims in published maps and institutional affiliations.

The online version of the original article can be found at https://doi.org/ $10.1007 / \mathrm{s} 40688-021-00365-6$

Stefan C. Dombrowski

sdombrowski@rider.edu

1 Department of Graduate Education, Leadership, and Counseling, Rider University, 2083 Lawrenceville Road,

Lawrenceville, NJ 08648, USA

2 William \& Mary, Williamsburg, VA, USA

3 Baylor University, Waco, TX, USA

4 Eastern Illinois University, Charleston, IL, USA

5 Kennedy Krieger Institute, Johns Hopkins University School of Medicine, Baltimore, MD, USA 